International Journal of Advanced Technology in Mechanical, Mechatronics and Materials

(IJATEC)

Vol. 01, No. 2 (2020) 66-75

(C) Institute for Research on Innovation and Industrial System (IRIS)

\title{
A Crane Robot of Three Axes Dimensional Using Trajectory Planning Method
}

\author{
Triyanto Pangaribowo*a, Muhammad Hafizd Ibnu Hajara, Julpri Andikaa, Adi Juliyanto ${ }^{\text {b }}$ \\ ${ }^{a}$ Department of Electrical Engineering, Faculty of Engineering, Universitas Mercu Buana, Jakarta, Indonesia \\ ${ }^{b}$ Electrical Engineering Bachelor Programme, Faculty of Engineering, Universias Mercu Buana, Indonesia
}

\begin{abstract}
This study aims to design a crane robot that has good performance with good stability, good accuracy in the gripper clamping the object at the point of balance and reach the target location well. The crane controller is installed with US-100 ping sensor and proximity infrared sensor to detect position of object. The robot crane moves on the $\mathrm{x}, \mathrm{y}$ and $\mathrm{z}$ axes or in three dimensions using motors as actuator and it can be adjusted with motor drive. The crane moves on the $\mathrm{x}$ and $\mathrm{y}$ axes using DC motor and $\mathrm{z}$ axis using servo motor. The crane automatically moves when it detects an object. The crane's movement uses the trajectory determination method by maintaining speed. Finally, the average accuracy of the gripper clamping exactly at the midpoint of the object is $93 \%$. The length of the object when it is clamped has an accuracy of $95 \%$. The performance of the crane robot is evaluated to transfer an object to the destination location takes 11 seconds with a track length of $86.055 \mathrm{~cm}$.
\end{abstract}

Keywords: a crane robot; three axes; trajectory; Control

DOI: $10.37869 /$ ijatec.v1i2.20

Received 6 May 2020; Accepted 31 July 2020; Available online 7 August 2020

(c) 2020 IRIS Publisher. All rights reserved.

\section{Introduction}

Cranes are machines that are used for transporting heavy loads or hazardous materials from one place to another place. Cranes can be controlled by using several approaches for their operations, which usually involve the process of gripping, lifting, transporting the load, then lowering and ungripping the load [1]. Crane is widely used to move a heavy object from one place to another not only in manufacturing industry but also in-service industry. There are a lot of cranes that are used to move objects in service industry such as in port container terminals, port terminals, warehouses, repairing services, etc. [2]. Among these kinds of cranes, over- head crane is the most representative and commonly used crane [3].

They can be classified based on the degrees of freedom that the support mechanism offers at the suspension point. A crane consist of a hoisting mechanism and a support mechanism [4]. As one of the important transportation equipments, cranes are successfully applied in diverse elds for the heavy cargoes transportation [5]. In fact, each crane model is controlled with a dedicated control algorithm that cannot be modified, accessed, or replaced at runtime[6]. Many industries rely on cranes for efficiently executing storage and retrieval operations of goods. Areas of application are, for instance, container logistics in seaports and warehousing operations in automated storage and retrieval systems[7]. Cranes operated at warehouses are an important asset for many industries which have to temporarily store products on their way from manufacturers to consumers. Such warehouses are more of a need and a significant operational cost that must be minimized [8].

Automated storage/retrieval systems (ASRSs) are widely used in warehouses and distributions centers all around the world[9]. Automated Storage/Retrieval Systems (AS/RS) have an important 
role in the improvement of the performance of automated manufacturing systems, warehouses and distribution centers [10]. The pick \& place task for a robot with movable platform located is present at the most of the industrial. In the most commercial robots; where navigation is required in a closed environment (for example, at the factory), ultrasonic sensors are suitable [11]. System for cranes should be equipped with relevant equipment such as actuators and controllers [12]. Concerning traditionally overhead cranes, nowadays, the dynamical modeling and control, in order to eliminate swing effects and ensure system stability [13]. As a crane is an expensive equipments it is interesting to optimize its performance to improve its utility [14]. To achieve efficient crane control and accurate positioning, the speed for each direction is predetermined according to crane system specifications such as maximum speed, acceleration and deceleration [15]. Crane control contains position controller and speed controller[16]. The task of the robot crane is to find a path free of collisions starting position moves to the target position in a environment with obstacles [17]. To increase productivity, the overhead crane transports the payload as fast as possible to its destination [18]. Basically, the crane drive system uses a motor. Control of crane operations is carried out through motor movement control[19]. There are three basic objectives in designing a robot free from collisions, maintaining a constant distance from the wall, and moving smoothly at high speeds[20].

In this study the focus on problem solving of gripper accuracy and transfer objects precisely to the destination. The accuracy of the gripper to clamping the object right on the balance point so the object does not fall when it lift. To achieve research objectives using devices such as ultrasonic sensor, infrared and rotary encoder. Object distance calculation is obtained by comparison of ultrasonic sensor data and photoelectric infrared sensor data. Servo motor as a gripper actuator pinches an object when the $\mathrm{x}$ and $\mathrm{y}$ axes are in the right position the control system uses a microcontroller as the central controller. This robot crane is designed to have the ability to work automatically to move object from one place to another. This robot crane is also able to return to the starting point after delivering the object.

\section{Research Methodology}

Research method by designing hardware and software. The design of hardware and software explained in this section.

\subsection{Design of hardware}

The crane robot block diagram is shown in Figure 1.

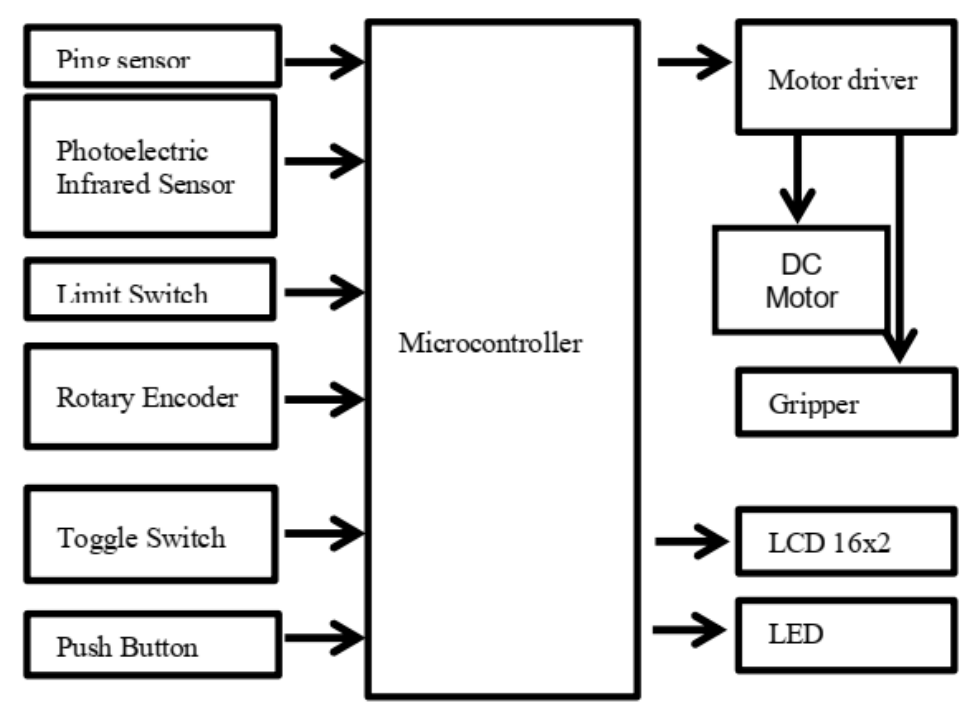

Figure 1. Block diagram input and output control system

The microcontroller system is a microprocessor as center of the device central to all systems and organizes all activities input / output system [21], [22]. Based on the block diagram in figure 1, the crane robot control system consists of an input block, a control block and an output block. Input block consists of ping sensor, photoelectric infrared sensor, rotary encoder, limit switch, toggle switch and 
push button. The controller block uses Arduino ATmega 2560. The output block consists of Motor driver, LCD and LED.

This project using the ping US-100 high precision ultrasonic range sensor. The US-100 Ultrasonic Sensor can measure or detect the object in the range of $2 \mathrm{~cm}$ to $450 \mathrm{~cm}$ distance and high precision up to $3 \mathrm{~mm}$. This US-100 has $2.4 \mathrm{~V}$ to $4.5 \mathrm{~V}$ wide voltage input range. To obtain a distance measurement, set the Trig / TX pin high for at least 50 microseconds then set it low to trigger the measurement. This project also using proximity sensor/switch E18-D80NK. easy to use Infrared sensor with a long detection distance and has less interference by visible light. The sensor has specifications input voltage $+5 \mathrm{~V}$ DC, current consumption $>25 \mathrm{~mA}(\mathrm{~min}) \sim 100 \mathrm{~mA}$ (max), sensing range $3 \mathrm{~cm}$ to $80 \mathrm{~cm}$ (depends on obstacle surface).

\subsection{The robot movement}

The movement of robotic cranes is carried out to determine and consider how much distance is obtained with the number of rotations of the DC motor on the $\mathrm{z}$ axis. The object transfer scenario from point $(30,30)$ to point $(60,60)$. Based on the movement of the robot crane that moves from the starting point $(0,0)$ as follows.

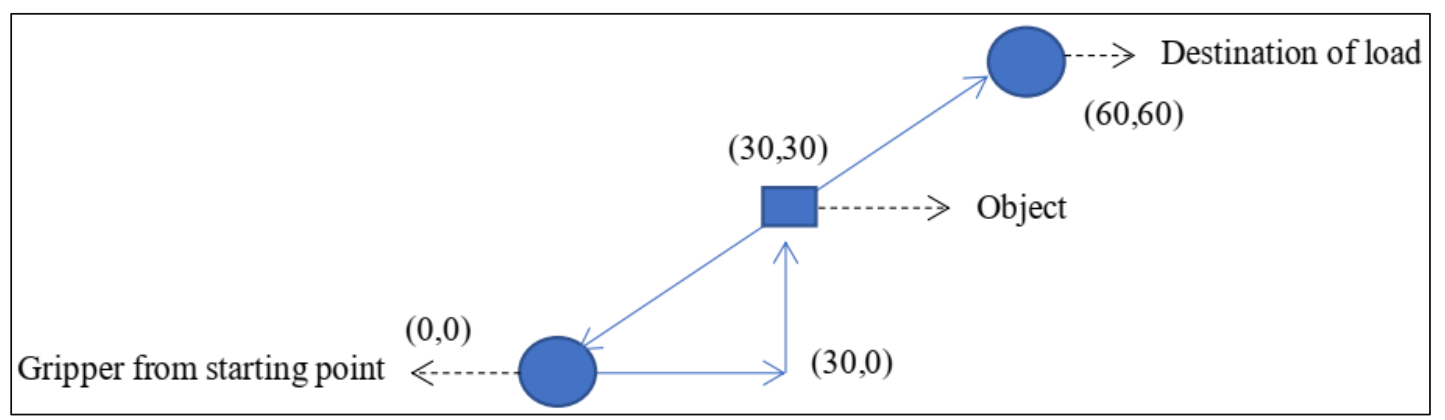

Figure 2. Robotic crane trajectory

for more detailed trajectory of robot crane movements on the $\mathrm{x}$ and y axes shown in Figure 3.

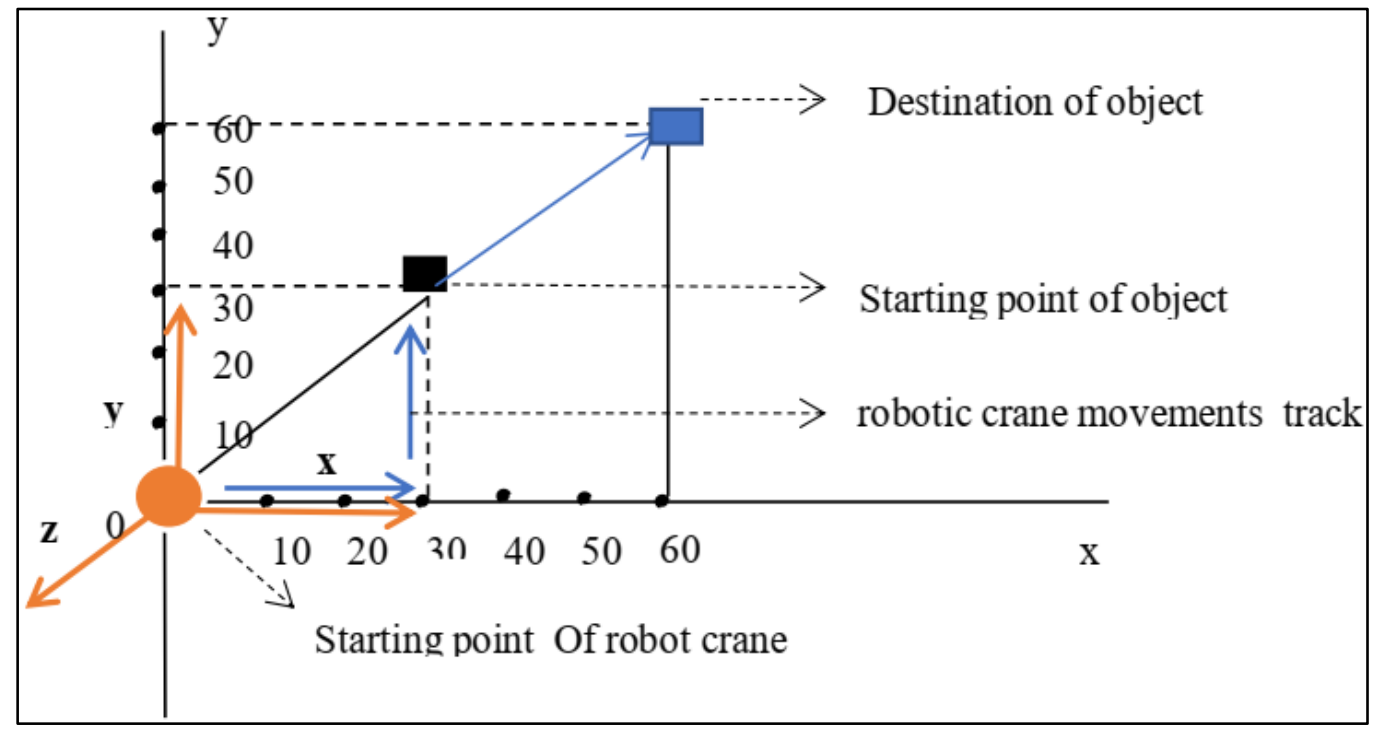

Figure 3. The movement of the robot crane with the point of the object $(30,30)$

When the robot crane has detected the position of the object, then picks it up through two motions. the first move on the $\mathrm{x}$ axis and the second move on the $\mathrm{y}$ axis. After the robot crane delivers the object to the destination location, the robot returns directly to the starting point $(0,0)$. The robot moves from points $(0,0),(30,0),(30,30)$ and to the final destination point $(60,60)$. The gripper will pick up and carry the object at exactly the right point $(30,30)$. The second path of the robot moves straight from point $(60,60)$ back to the starting position $(0.0)$. The distance between the robot crane and position of object can be calculated using the following triangle formula. 


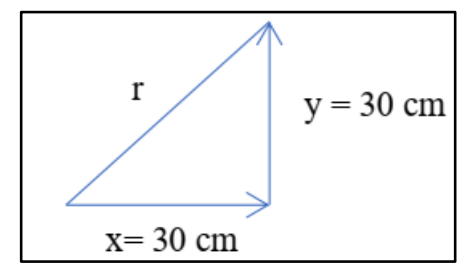

Figure 4. The distance of robot crane to the object

$$
r=\sqrt{x^{2}+y^{2}}
$$

Based on the Equation 1 the actual distance robot crane to object as follows:

$$
r=\sqrt{30^{2}+30^{2}}=42,42 \mathrm{~cm}
$$

$r$ is the actual distance. the movement of the robot crane from point $(0,0)$ to $(30,30)$ is not like when detecting the initial load, but directly straight.

\subsection{Flow chart of control program}

Robot crane works by giving voltage from power supply to the microcontroller, and motor driver. The first stage robot crane moves the DC motor as an actuator in sequence from the $\mathrm{x}$-axis to the $\mathrm{y}$ axis. When the start button is pressed, the DC motor ( $\mathrm{x}$-axis) moves, the Ping sensor located on the $\mathrm{x}$-axis reflects ultrasonic waves as a comparator for the calculation of the $\mathrm{x}$-axis point to the point obtained by the photoelectric infrared sensor. When the load has been detected by a photoelectric infrared sensor, the rotary encoder on the motor ( $\mathrm{x}$ axis) calculates and compares the distance of the ping sensor on the $\mathrm{x}$ axis. After getting the load position correctly the gripper moves to take the load and lift it. After the item is raised the gripper motor, the $\mathrm{x}$-axis motor and the y-axis motor move together to move the item to the setup position. Then the motor returns to the starting position.

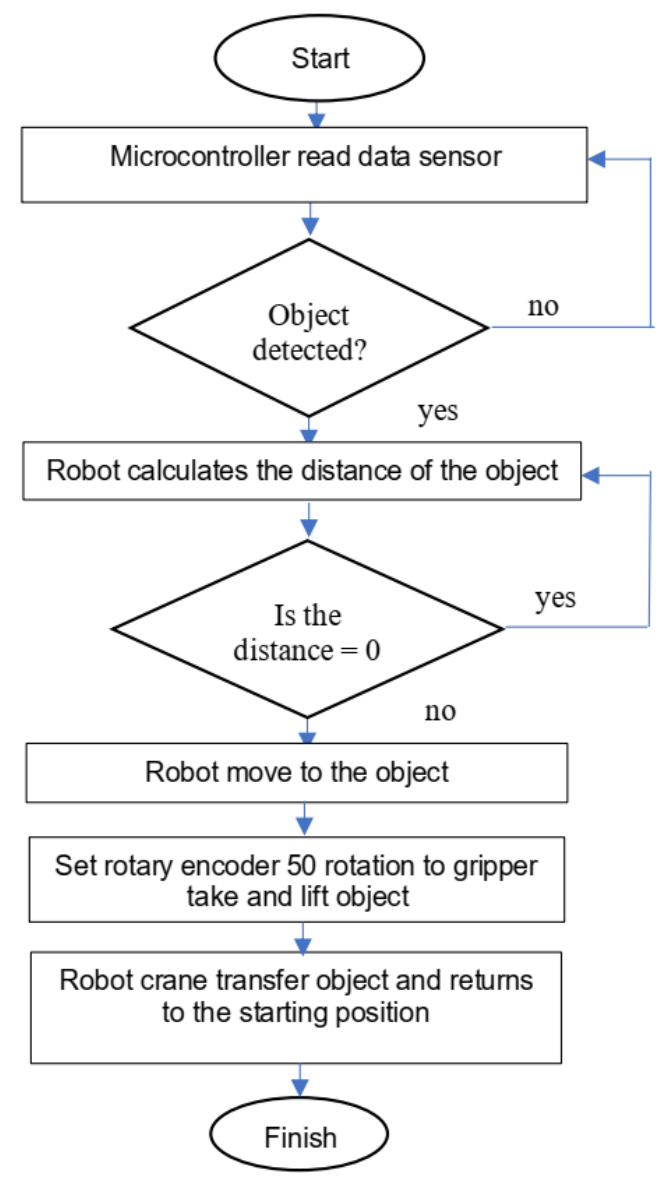


Figure 5. The flow chart for the robotic crane control program

Based on the flow chart figure 3 consist of two steps generally. The first step, the load detected and sensor sends data to the microcontroller to be processed, the second step of the microcontroller gives the command to the motor to move to the load. after the gripper is just above the load, it will be moved according to the specified location. Then the gripper returns to the starting position after delivering the load to the location.

A robotic crane is designed to be able to move in 3 dimensions $\mathrm{x}, \mathrm{y}$ and $\mathrm{z}$. Movement on the $\mathrm{x}$ and $\mathrm{y}$ axis uses dc motor and for the $\mathrm{z}$ axis uses a servo motor. So totally, there are 4 actuators used in this research project. Two DC motors for moving on the $\mathrm{x}$ and $\mathrm{y}$ axes, and 2 servo motors for moving on the $\mathrm{z}$ axis and gripper.

\section{Results and Discussions}

Testing the control system on the robot crane is needed to find out the performance. The testing method used is to measure and record the results of the experiment.

\subsection{Testing the relationship between current and the load}

Testing the power supply circuit to determine the feasibility of the power supply in providing voltage and current to the control system and some microcontroller outputs and protecting the device from over-current. The energy source for supplying electrical energy to the control system and the load uses 12 volts and $3 \mathrm{~A}$ for current.

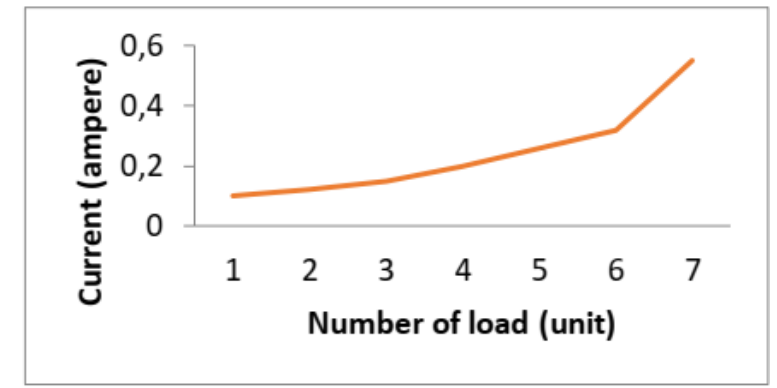

Figure 6. the relationship between current and number of loads

Figure 6 shows the relationship between current and total load. The current increases due to the increasing number of loads. Likewise, in the power consumption test as shown in Figure 7. Loads consist of microcontroller, sensors, LED, LCD, motor driver, DC motor, servo motor and gripper.

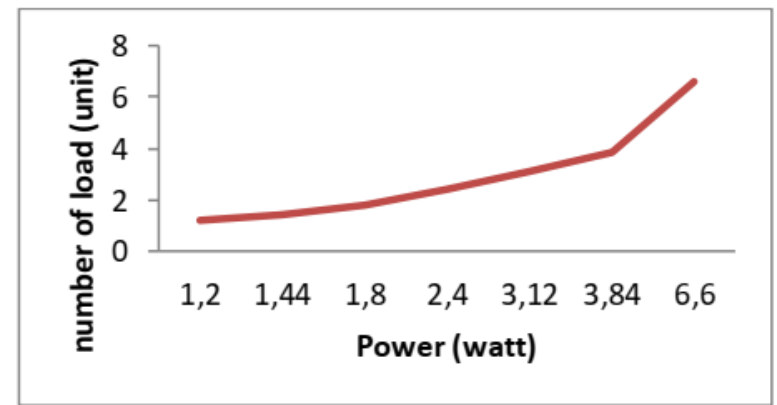

Figure 7. the relationship between power and number of loads

Based on the test results for the power supply, the supply voltage is stable when the connected systems are active. When the system is turned on, no voltage drop occurs. The current increases when all loads are activated. The current increase is not significant, so it is a normal state. This can be said that the power supply is in good condition and is suitable for use. 
Gripper accuracy is how the gripper can pinch precisely at the midpoint of the object. The goal is to maintain the balance, so the object does not fall when the gripper lifts the object.

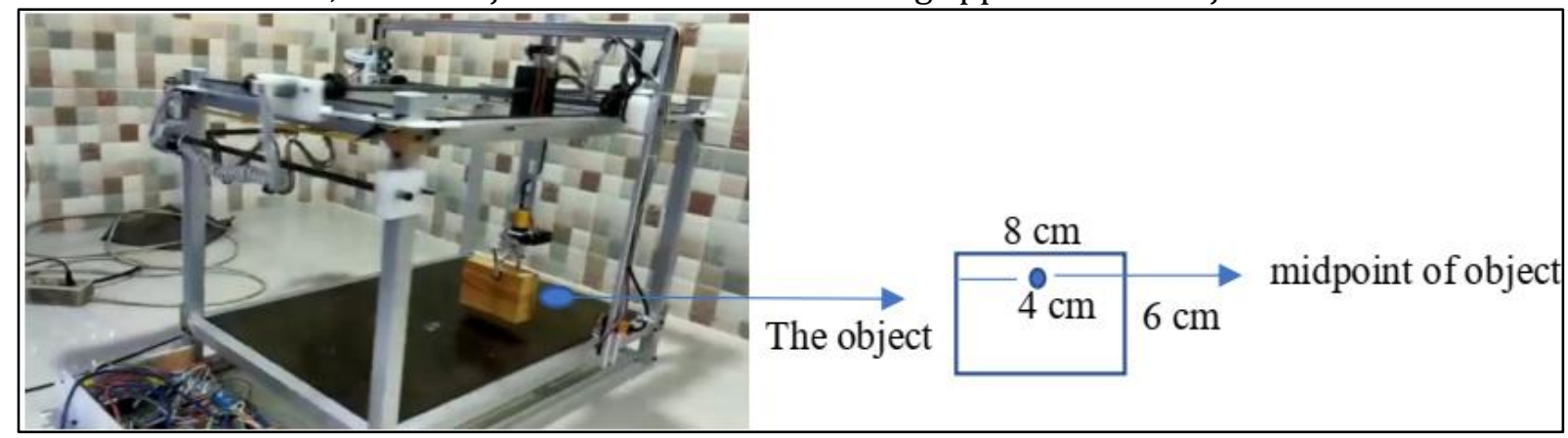

Figure 8. The midpoint of object as gripper target

Based on Figure 6, the object has a length of $8 \mathrm{~cm}$ and a height of $6 \mathrm{~cm}$. the specified midpoint of the object is $4 \mathrm{~cm}$ taken from the midpoint of the object's length. To get the gripper's accuracy in pinching the midpoint of the object, in this experiment 5 times were carried out, the results as shown in Table 1.

Table 1. The Experiment results of gripper accuracy to clamp midpoint of object

\begin{tabular}{cccc}
\hline No & $\begin{array}{c}\text { Experiment Result } \\
(\mathrm{cm})\end{array}$ & $\begin{array}{c}\text { Target of the object point } \\
(\mathrm{cm})\end{array}$ & $\begin{array}{c}\text { Accuracy } \\
(\%)\end{array}$ \\
\hline 1. & 3.7 & 4 & $93 \%$ \\
2. & 3.6 & 4 & $90 \%$ \\
3. & 3.8 & 4 & $95 \%$ \\
4. & 3,7 & 4 & $93 \%$ \\
5. & 3.8 & 4 & $95 \%$ \\
\hline
\end{tabular}

Average gripper accuracy $=\frac{\sum \% \text { Accuracy }}{\mathbf{n} \text { Experiment }}$

Based on Equation 2 the average accuracy can be calculated as follows:

$$
\text { Average accuracy }=\frac{93 \%+90 \%+95 \%+93 \%+95 \%}{5}=93 \%
$$

\subsection{Gripper accuracy test results for picking and lifting objects}

The important thing in this robot crane is the movement of the gripper up and down to pick up and lift objects. The gripper specifications used in this project have clamp max open is $55 \mathrm{~mm}$, clamp total length $108 \mathrm{~mm}$, clamp total width $98 \mathrm{~mm}$ when the clamp open.

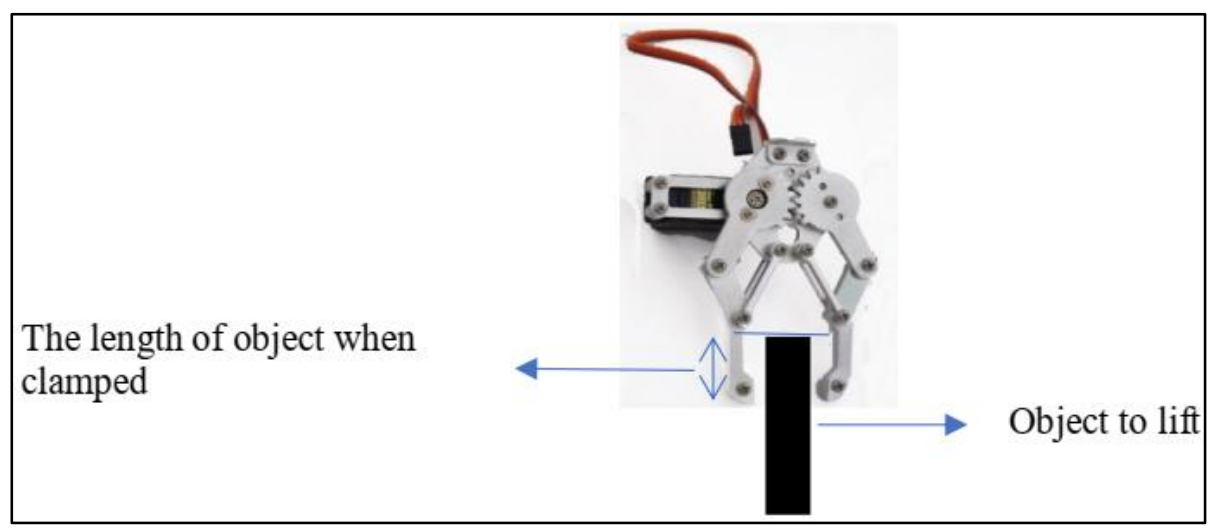

Figure 9. Aluminium alloy robotic claw

The purpose of testing the rotary encoder on the gripper so that the gripper does not hit the ojek when the downward movement takes an object. The rotation of the knob on the $\mathrm{z}$ axis as a driving 
motor when raising and lowering the gripper, the encoder is needed to determine and calculate the distance of the gripper down so that it does not hit the object.

Table 2. The Experiment results of gripper accuracy to clamp midpoint of object

\begin{tabular}{cccc}
\hline No. & Total rotation of DC Motor & Actual distance & Target \\
\hline 1 & 50 rotation & $6 \mathrm{~cm}$ & $6 \mathrm{~cm}$ \\
2 & 50 rotation & $6 \mathrm{~cm}$ & $6 \mathrm{~cm}$ \\
3 & 50 rotation & $7 \mathrm{~cm}$ & $6 \mathrm{~cm}$ \\
4 & 50 rotation & $6 \mathrm{~cm}$ & $6 \mathrm{~cm}$ \\
5 & 50 rotation & $6.5 \mathrm{~cm}$ & $6 \mathrm{~cm}$ \\
\hline
\end{tabular}

Based on the Figure 9 length of gripper to clamp object $3 \mathrm{~cm}$ so if the gripper moves up and down totally $6 \mathrm{~cm}$. Table 2 shows the results of distance measurements with a target of $6 \mathrm{~cm}$. To reach a distance of $1 \mathrm{~cm}$ requires 8 rotations so for 50 rotation about $6 \mathrm{~cm}$. Based on the data in table 2, the gripper mileage for up and down movements compared to the target distance is calculated as follows.

$$
\text { Gripper rotation accuracy }=\frac{100 \%+100 \%+86 \%+100 \%+92 \%}{=5}=96 \%
$$

Accuracy is affected by rounding of numbers, gripper grips, and object dimensions. In the experimental results table 2 shows the safe distance when the gripper took the object did not hit it because the gripper has a total length of about $10.8 \mathrm{~cm}$.

\subsection{Testing the movement of the robot from the point of $(0,0)$ to $(60,40)$}

The mechanical design in figure 10 has a length of $60 \mathrm{~cm}$ and a width of $40 \mathrm{~cm}$. Figure 10 shows the movement of the robot crane from detecting until delivering object to the final location.

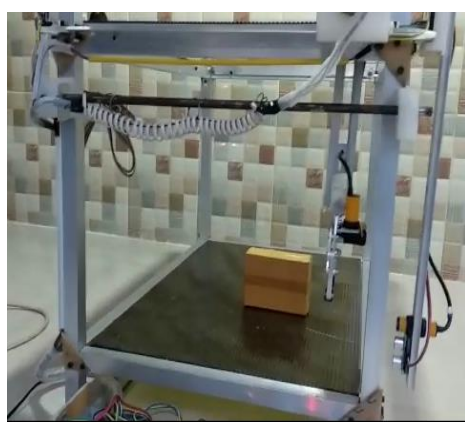

(a)

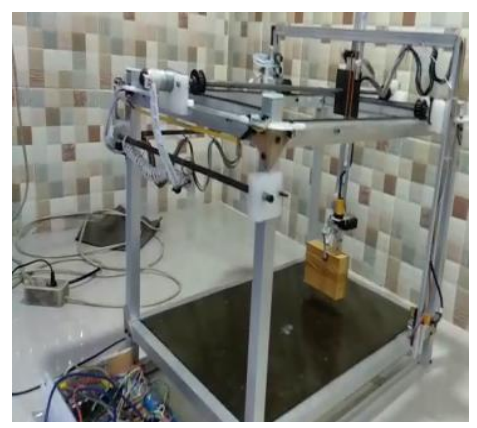

(b)

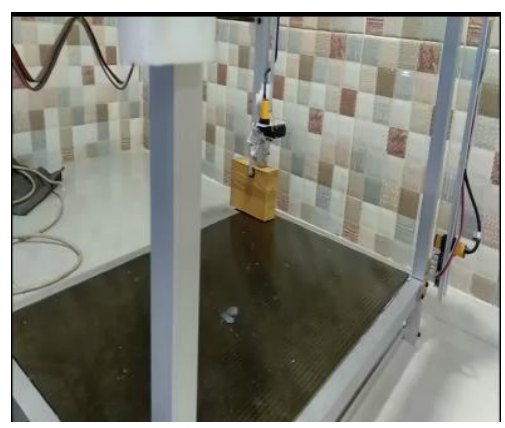

(c)

Figure 10. (a) Starting position of the object, (b) the crane is lifting and carrying the object to the final location, (c) the object has arrived at the final location

The object is placed at the center point of the $\mathrm{x}$ and $\mathrm{y}$ axes $(30,20)$. The object is transferred to point $(60,40)$, for more details explained in Figure 11.

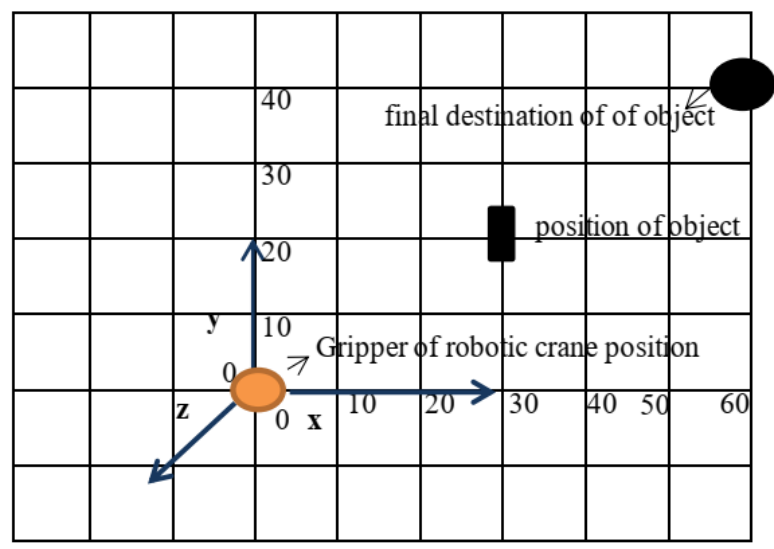


Figure 11. Robotic crane paths on the $\mathrm{x}$ and $\mathrm{y}$ axes

To transfer objects from point $(30,20)$ to end point $(60,40)$, robot crane moves through several points starting from $(0,0),(0,30),(30,20)$ and finally to point $(60,40)$. The total length of the robot's trajectory to transfer objects from the starting point (0.0) to the end point (60.40) is calculated based on the trajectory in Figure 12.

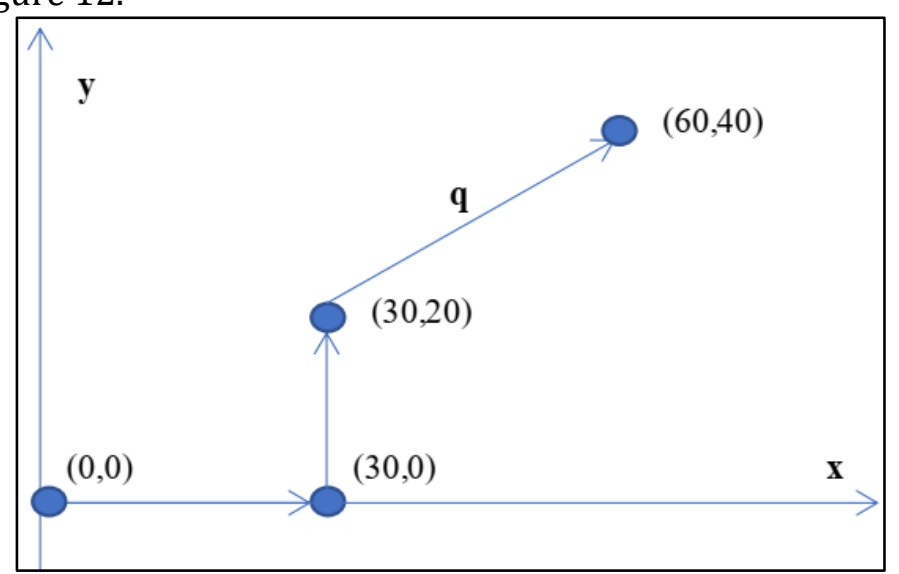

Figure 12. The length of the robot's trajectory for transferring objects

$\mathrm{q}$ is calculated as follows:

$$
\begin{aligned}
& q=\sqrt{30^{2}+20^{2}} \\
& q=36.055 \mathrm{~cm}
\end{aligned}
$$

$q=$ the length of the robot's trajectory for transferring objects from $(30,20)$ to point of $(60,40)$.

So, the total length of the robot's trajectory to deliver the object $86,055 \mathrm{~cm}$. based on testing the duration of time needed to transfer an object with a path length 86,055 cm, shown in Table 3.

Table 3. The result of robot travel time based on the length of the track

\begin{tabular}{clcc}
\hline No & \multicolumn{1}{c}{ Point of Trajectory } & Length of track $(\mathrm{cm})$ & Time $(\mathrm{s})$ \\
\hline 1. & $(0,0)$ to $(30,0)$ & 30 & 2.4 \\
2. & $(30,0)$ to $(30,20)$ & 20 & 1.6 \\
3. & $(30,20)$ - loading process & - & 2.06 \\
3. & $(30,20)$ to $(60,40)$ & 36,055 & 2.88 \\
4. & $(60,40)-$ unloading process & - & 2.06 \\
\hline \multicolumn{2}{c}{ Total } & 86,055 & 11 \\
\hline
\end{tabular}

Loading process is the process of gripper going down until lifting an object. The loading process takes 2.06 seconds before the object is transferred to the destination location. And also, for the unloading process takes 2.06 seconds. In total the time taken by the robot crane to travel $86.055 \mathrm{~cm}$ from point 0.0 to point 60.40 is 11 seconds. So, the average speed of the robot is calculated as follows.

$$
\text { Avergae speed }=\frac{s}{t}
$$

Based on Equation 3 the average speed of the robot as follows:

$$
\text { Average speed }=\frac{86.055 \mathrm{~cm}}{11 \mathrm{~s}}=7,2 \mathrm{~cm} / \mathrm{s}
$$

$\mathrm{S}=$ the total length of the robot's trajectory for object transfer

$\mathrm{t}=$ total time the robot traveled the length of the track

After the robot puts the object to the destination, then the robot returns to the starting position from point 60,40 directly to 0,0 . 


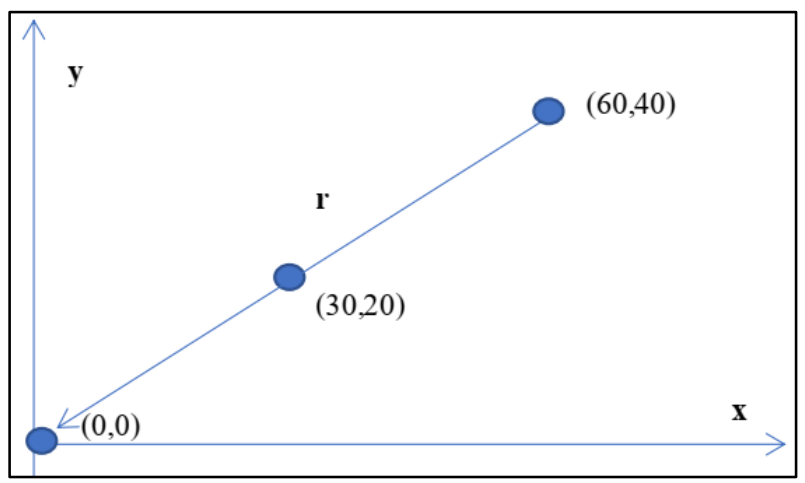

Figure 13. The length of the robot's trajectory returns to the starting point

Based on figure 13, the length of the robot's trajectory to return to the starting point is calculated as follows:

$$
r=\sqrt{60^{2}+40^{2}}=72.11 \mathrm{~cm}
$$

$\mathrm{r}=$ the length of the robot's trajectory returns to the starting point.

The time taken by the robot to return to the starting position with a distance of $72.11 \mathrm{~cm}$ is 4.98 seconds, so the speed of the robot returning to base has been calculated as follows

$$
\text { Speed }=\frac{72.11 \mathrm{~cm}}{4.98 \mathrm{~s}}=14,48 \mathrm{~cm} / \mathrm{s}
$$

\section{Conclusions}

Based on the data and analysis results, the robot has a good performance with a good precision and accuracy. The robot gripper has been able to clamp objects at the midpoint with an accuracy of $93 \%$. The length of the object when it is clamped has an accuracy of $95 \%$. The robot also has a high stability when carrying objects to the destination location. Robot gripper can lift right in the middle of the object, so that the object does not fall when raised. The average speed of robots to deliver object with a track distance of $86.055 \mathrm{~cm}$ is $7,2 \mathrm{~cm} / \mathrm{s}$, while returning to base takes 4.98 seconds with the length of track is $72.11 \mathrm{~cm}$

In further research, crane robot can be developed to overcome many obstacles. Support for internet connection so that it can be controlled with a mobile application. The selection of sensors for distance detection needs to be considered in terms of precision.

\section{References}

[1] L. Ramli, Z. Mohamed, A. M. Abdullahi, H. I. Jaafar, and I. M. Lazim, "Control strategies for crane systems: A comprehensive review," Mech. Syst. Signal Process., vol. 95, pp. 1-23, 2017. https://doi.org/10.1016/j.ymssp.2017.03.015

[2] Z. Zhou and L. Li, "Optimal cyclic single crane scheduling for two parallel train oilcan repairing lines," Comput. Oper. Res., vol. 39, no. 8, pp. 1850-1856, 2012. https://doi.org/10.1016/i.cor.2011.06.002

[3] Z. Sun, X. Zhao, Z. Sun, F. Xiang, and C. Mao, "Optimal sliding mode controller design based on dynamic differential evolutionary algorithm for under-actuated crane systems," IEEE Access, vol. 6, pp. 67469-67476, 2018. https://doi.org/10.1109/ACCESS.2018.2872062

[4] E. M. Abdel-rahman, A. H. Nayfeh, and Z. N. Masoud, "Journal of," pp. 863-908, 2003. https://doi.org/10.1177\%2F1077546303009007007

[5] Z. Sun, Y. Bi, X. Zhao, Z. Sun, C. Ying, and S. Tan, "Type-2 Fuzzy Sliding Mode Anti-Swing Controller Design and Optimization for Overhead Crane," IEEE Access, vol. 6, pp. 51931-51938, 2018. https://doi.org/10.1109/ACCESS.2018.2869217

[6] F. Sanfilippo, L. I. Hatledal, A. Styve, K. Y. Pettersen, and H. Zhang, "Integrated Flexible Maritime Crane Architecture for the Offshore Simulation Centre AS (OSC): A Flexible Framework for Alternative Maritime Crane Control Algorithms," IEEE J. Ocean. Eng., vol. 41, no. 2, pp. 450-461, 2016. https://doi.org/10.1109/IOE.2015.2439891

[7] N. Boysen, D. Briskorn, and F. Meisel, "A generalized classification scheme for crane scheduling 
with interference," Eur. J. Oper. Res., vol. 258, no. 1, pp. 343-357, 2017. https://doi.org/10.1016/i.ejor.2016.08.041

[8] S. Heshmati, T. A. M. Toffolo, W. Vancroonenburg, and G. Vanden Berghe, "Crane-operated warehouses: Integrating location assignment and crane scheduling," Comput. Ind. Eng., vol. 129, no. May 2018, pp. 274-295, 2019. https://doi.org/10.1016/j.cie.2019.01.039

[9] N. Boysen and K. Stephan, "A survey on single crane scheduling in automated storage/retrieval systems," Eur. J. Oper. Res., vol. 254, no. 3, pp. 691-704, 2016. https://doi.org/10.1016/i.ejor.2016.04.008

[10] B. Salah, O. Janeh, B. Noche, T. Bruckmann, and S. Darmoul, "Design and simulation based validation of the control architecture of a stacker crane based on an innovative wire-driven robot," Robot. Comput. Integr. Manuf., vol. 44, pp. 117-128, 2017. https://doi.org/10.1016/i.rcim.2016.08.010

[11] V. Krasniqi, S. Buza, A. Pajaziti, and F. Krasniqi, "Control algorithm of a pick and place three dimensional robots," IFAC Proc. Vol., vol. 15, no. PART 1, pp. 440-443, 2013. https://doi.org/10.3182/20130825-4-US-2038.00029

[12] B. Rokseth, S. Skjong, and E. Pedersen, "Modeling of Generic Offshore Vessel in Crane Operations with Focus on Strong Rigid Body Connections," IEEE J. Ocean. Eng., vol. 42, no. 4, pp. 846-868, 2017. https://doi.org/10.1109/JOE.2016.2614584

[13] L. Scalera, P. Gallina, S. Seriani, and A. Gasparetto, "Cable-Based Robotic Crane (CBRC): Design and Implementation of Overhead Traveling Cranes Based on Variable Radius Drums," IEEE Trans. Robot., vol. 34, no. 2, pp. 474-485, 2018.https://doi.org/10.1109/TR0.2018.2791593

[14] G. N. Maschietto, Y. Ouazene, M. G. Ravetti, M. C. de Souza, and F. Yalaoui, "Scheduling cranes to retrieve steel coils in a warehouse," IFAC-PapersOnLine, vol. 49, no. 12, pp. 1020-1025, 2016. https://doi.org/10.1016/j.ifacol.2016.07.576

[15] K. H. Cheng, "Adaptive B-spline-based fuzzy sliding-mode control for an auto-warehousing crane system," Appl. Soft Comput. J., vol. 48, pp. 476-490, 2016. https://doi.org/10.1016/j.asoc.2016.04.002

[16] M. Gniadek, "Usage of input shaping for crane load oscillation reduction," 2015 20th Int. Conf. Methods Model. Autom. Robot. MMAR 2015, pp. 278-282, 2015. https://doi.org/10.1109/MMAR.2015.7283887

[17] S. H. Chia, K. L. Su, J. H. Guo, and C. Y. Chung, "Ant colony system based mobile robot path planning," Proc. - 4th Int. Conf. Genet. Evol. Comput. ICGEC 2010, pp. 210-213, 2010. https://doi.org/10.1109/ICGEC.2010.59

[18] M. Zhang et al., "Adaptive Proportional-Derivative Sliding Mode Control Law with Improved Transient Performance for Underactuated Overhead Crane Systems," IEEE/CAA J. Autom. Sin., vol. 5, no. 3, pp. 683-690, 2018.https://doi.org/10.1109/IAS.2018.7511072

[19] R. N. Hasanah, M. F. P. Perdana, R. Santoso, and H. Suyono, "Design and construction of a singlearm crane miniature for stevedoring," 2017 20th Int. Conf. Electr. Mach. Syst. ICEMS 2017, 2017. https://doi.org/10.1109/ICEMS.2017.8056167

[20] C. H. Hsu and C. F. Juang, "Multi-objective continuous-ant-colony-optimized FC for robot wallfollowing control," IEEE Comput. Intell. Mag., vol. 8, no. 3, pp. 28-40, 2013. https://doi.org/10.1109/MCI.2013.2264233

[21] A. Adriansyah and A. W. Dani, "Design of small smart home system based on arduino," Proc. - 2014 Electr. Power, Electron. Commun. Control Informatics Semin. EECCIS 2014. conjunction with 1st Jt. Conf. UB-UTHM , pp. 121-125, 2014. https://doi.org/10.1109/EECCIS.2014.7003731

[22] A. Adriansyah, A. W. Dani, and G. I. Nugraha, "Automation control and monitoring of public street lighting system based on internet of things," ICECOS 2017 - Proceeding 2017 Int. Conf. Electr. Eng. Comput. Sci. Sustain. Cult. Herit. Towar. Smart Environ. Better Futur., pp. 231-236, 2017. https://doi.org/10.1109/ICECOS.2017.8167140 